\title{
Museos virtuales iberoamericanos en español como contextos de enseñanza y aprendizaje de las ciencias naturales
}

\author{
Micaela del Valle Rasino \\ Facultad de Ciencias Exactas, Físicas y Naturales, Universidad Nacional de Córdoba. Córdoba. Argentina. \\ mikirasino@gmail.com \\ ORCID: https:/ / orcid.org/0000-0002-6266-0392
}
Ximena Ayelén Broiero
Facultad de Ciencias Exactas, Físicas y Naturales, Universidad Nacional de Córdoba. Córdoba. Argentina. broieroximena@gmail.com
ORCID: bttps:// orcid.org/0000-0002-3517-3855

\section{Leticia Garcia-Romano}
CONICET, Departamento de Enseñanza de la Ciencia y la Tecnología, Facultad de Ciencias Exactas, Físicas y Naturales, Universidad Nacional de Córdoba. Córdoba. Argentina. leticia.garcia@unc.edu.ar
ORCID: http:/ / orcid.org/0000-0003-3552-0287

[Recibido: 19 Diciembre 2018. Revisado: 26 Marzo 2019. Aceptado: 23 Agosto 2019]

\begin{abstract}
Resumen: Los museos de ciencias (MC) tienen la misión de contribuir a que la ciencia se incorpore a la cultura general de la sociedad. Su colaboración con las escuelas supone incrementar las oportunidades para aprender ciencias tanto para docentes como para los alumnos. En los últimos años, los museos se han involucrado en el mundo informático, dando lugar a la existencia de museos virtuales que ofrecen experiencias educativas significativas sin necesidad de acudir al espacio físico de los mismos. En este contexto, se caracterizaron museos virtuales iberoamericanos en español como contextos para la enseñanza y el aprendizaje de las ciencias naturales. Se procedió a realizar un análisis de contenido de 28 museos a través de tres dimensiones: TIC, Didáctica y Ciencia. A partir de los resultados obtenidos se puede concluir que la mayoría de los museos virtuales analizados evidenciaron un gran avance en la dimensión "TIC" pero es necesario aumentar su interactividad. Con respecto a la dimensión "Didáctica" es importante que los museos virtuales incorporen recursos que aborden tanto contenidos conceptuales como procedimentales y actitudinales. En lo que atañe a la dimensión "Ciencia" es relevante que los museos brinden una visión de ciencia aplicada que contemple la historicidad del conocimiento. Se recomienda que los docentes seleccionen aquellos escenarios de aprendizaje que posean características superadoras en las dimensiones de análisis estudiadas, aprovechen las redes sociales de los museos y construyan actividades específicas que den sentido al trabajo áulico con un determinado museo virtual.
\end{abstract}

Palabras clave: Museos virtuales, TIC, Didáctica, Ciencia, Escuela.

Ibero-American Virtual Museums in Spanish as contexts for the teaching and learning of science

Abstract: The mission of science museums is to contribute to the incorporation of science in the general culture of society. Their collaboration with schools entails increasing opportunities for both teachers and students to learn science. In recent years, museums have got involved in the IT world; resulting in the existence of virtual museums that offer meaningful educational experiences without having to physically go to their premises. In this way, Ibero-American Virtual Museums in Spanish have been characterised as contexts for the teaching and learning of science. A content analysis of 28 museums was carried out considering three dimensions: ICT, Didactics and Science. According to the obtained results, it may be concluded that most of the virtual museums show important progress in the 'ICT' dimension but interactivity needs to be improved. As regards the 'Didactics' dimension, it is important that the virtual museums include resources that deal not only with conceptual but also with procedural and attitudinal content. In relation to "Science" dimension, it is relevant to provide a vision of applied science which takes the historicity of knowledge into consideration. It is recommended that teachers choose the learning scenarios which have the best characteristics concerning the

\author{
Revista Eureka sobre Enseñanza y Divulgación de las Ciencias \\ Universidad de Cádir: APAC-Eureka. ISSN: 1697-011X \\ bttp:/ / dx.doi.org/ 10.25267/Rev_Eureka_ensen_divulg_cienc.2020.v17.i1.1301 \\ http:// reuredc.uca.es
}


studied dimensions, that they exploit the social media of the museums and that they develop specific activities which are meaningful to the classroom practices around a specific virtual museum.

Keywords: Virtual Museums, ICT, Didactics, Science, School.

Para citar este artículo: Rasino M.V., Broiero, X.A., Garcia-Romano, L. (2020) Museos virtuales iberoamericanos en español como contextos de enseñanza y aprendizaje de las ciencias naturales. Revista Eureka sobre Enseñanza y Divulgación de las Ciencias 17(1), 1301. doi: 10.25267/Rev_Eureka_ensen_divulg_cienc.2020.v17.i1.1301

\section{Introducción}

Los museos de ciencias (MC) tienen la misión de contribuir a que la ciencia se incorpore a la cultura general de la sociedad ya que constituyen una de las instituciones sociales destinadas a conservar, exponer, investigar y divulgar el patrimonio cultural (Melgar y Donolo 2011). Una sociedad que se interese por la ciencia favorecerá un ambiente más oportuno para el desarrollo de la investigación científica y técnica, será más crítica para decidir sobre asuntos relacionados con estas áreas y, en general, estará más preparada para enfrentar las demandas del mundo actual (Reynoso-Haynes 2000). En este sentido, Segarra, Gadea, Vilches y Gil-Pérez (2017) y Armesto-Ramón, Martínez-Losada y García-Barros (2005) manifiestan que los MC pueden ser una herramienta útil para la reflexión crítica, contribuyendo así a la alfabetización de toda la ciudadanía.

En los últimos años, muchos $\mathrm{MC}$ han actualizado sus páginas web teniendo en cuenta las características del usuario, de tal modo que se ha automatizado la información de colecciones, se ha incorporado mayor contenido multimedia, se han vuelto más interactivos e inclusive se han conectado con distintas redes sociales. Además, se han creado páginas web con colecciones de artefactos electrónicos y recursos informativos independientes de cualquier museo físico, es decir, que solo existen en la red (Melgar, Gómez y Donolo 2009). Tal como señalan estos autores, a los primeros se los suele llamar museos digitales y a los segundos museos virtuales. Siguiendo a Elisondo y Melgar (2015) en este artículo llamaremos museos virtuales a ambos. En este contexto, los docentes de cualquier institución educativa que posean acceso a Internet, pueden ingresar a estos sitios y obtener recursos para ser trabajados en el aula junto a sus alumnos (Cebrián de la Serna y Gallego-Arrufat 2011).

Debido a que los sistemas educativos hacen frente al desafío de utilizar las tecnologías de la información y la comunicación (TIC) para brindar a sus alumnos herramientas y conocimientos necesarios para el siglo XXI (UNESCO 2004), los MC virtuales constituyen una propuesta interesante para dicho fin. Así, la apropiación de las TIC supone el desarrollo de una revolución tecnocientífica que cambia las prácticas humanas, y por lo tanto, sería esperable que también cambie las prácticas áulicas (Echeverría 2008).

Las investigaciones vinculadas con el aprendizaje en los museos han ido en consonancia con las de la investigación educativa en general, pasando primero por una etapa centrada en observar los comportamientos de las personas en estos espacios, analizando qué muestras resultaban más motivadoras y cómo se movían los visitantes a través del mismo; más adelante se exploró el sentido que le dan los participantes a su experiencia en el museo, focalizando en su conocimiento previo, sus objetivos y la apropiación que realizan los visitantes respecto al mensaje que el museo pretende transmitir; para finalmente incorporar una visión sociocultural, la cual se centra en el análisis de las formas en que los grupos de visitantes hablan, interactúan y cómo esas interacciones colaboran en el aprendizaje (Crowley, Pierroux y Knutson 2014).

De este modo, la literatura especializada sobre educación en los MC es profusa. Así, hay antecedentes que analizan la posibilidad de que los museos se conviertan en una oportunidad de reflexión crítica sobre la situación de crisis planetaria (González, Gil-Pérez y Vilches 2002); 
otros trabajos exploran las percepciones de educadores y estudiantes sobre este recurso (Ceballos-Aranda y Vílchez-López 2017; Morentín y Guisasola 2014; Banqué, Calafell y Bonil 2013; Viladot 2013; Guisasola y Morentín 2010); se describen experiencias y actividades didácticas diseñadas en ciertos museos (Roldán, Ulloa, Vargas, Chura y Pacheco 2017; Soler 2014; Cuenca, Wamba y Aguaded 2006; Varela Calvo y Stengler 2004); se analiza la naturaleza del aprendizaje que en ellos se produce (De Witt 2012, Rennie y Johnston 2004); se estudia la posibilidad de abordar este recurso en la formación inicial del profesorado (Morentín y Guisasola 2014; Morentín 2013); se describe el proceso de creación de un museo y los instrumentos socio-políticos necesarios para poder llevarlo a cabo (Alegret Tejero y Martí Llambrich 2003); se rescata el valor de un museo para el aprendizaje de una disciplina particular (Rábano y Rodrigo 2001); se investiga sobre la educación patrimonial (Estepa 2013) o se catalogan los propios museos según distintos criterios (Delgado-Buscalioni 2009; SegarraCastelló 2009; Vilches, Gil-Pérez, González M y González E 2006).

Además, es posible encontrar investigaciones que han definido las bases de la vinculación entre los museos y la virtualidad (Müller 2002), que han remarcado el valor de que docentes y estudiantes realicen visitas a museos virtuales (Becky 1998) y que caracterizan la introducción de tecnologías en los museos, tales como los juegos 3D, la realidad aumentada, entre otros (Yoon, Elinich, Wang, Steinmeier y Tucker 2012; Lepouras y Vassilakis 2004). Sin embargo, el potencial de los museos virtuales de ciencias naturales ha sido poco indagado, contando con el antecedente de Bowen, Bennett y Johnson (1998) en el que se analiza la evolución de dos museos virtuales de ciencias desde el punto de vista de los visitantes, el artículo de Audisio (2010), en el cual se infirió si las páginas web de los MC latinoamericanos eran herramientas útiles para la enseñanza de la Biología, y el trabajo de Melgar, Gómez y Donolo (2009) en el que se analizan en profundidad cuatro museos virtuales desde una perspectiva psicoeducativa.

En función de esto, el presente estudio propone caracterizar el potencial de los MC virtuales iberoamericanos en español como contextos de enseñanza y aprendizaje mediante el análisis de tres dimensiones:"TIC", "Didáctica" y "Ciencia".

\section{Referentes teóricos y antecedentes}

En la actualidad se reconoce que existe una amplia variedad de contextos y experiencias de aprendizaje. La educación formal comprende el sistema educativo altamente institucionalizado, cronológicamente graduado y jerárquicamente estructurado que se extiende desde los primeros años de la escuela primaria hasta los últimos años de la universidad. La educación no formal comprende toda actividad organizada, sistemática, educativa, realizada fuera del sistema oficial, para facilitar determinadas clases de aprendizaje a grupos particulares de la población. La educación informal implica un proceso que dura toda la vida y en el cual las personas adquieren conocimientos, habilidades, actitudes y modos de discernimiento mediante las experiencias diarias y su relación con el ambiente (Trilla, Gros, López y Martin 2003).

En el caso particular de los museos, Melgar, Gómez y Donolo (2009) sostienen que la consideración de estos tres contextos en la planificación de actividades resulta un elemento clave para brindar más y mejores oportunidades para aprender. Además, destacan el valor de los museos en la educación no formal, ya que ofrecen una serie de recursos que complementan la enseñanza formal. Por último, consideran que el desafío de los museos en el siglo XXI reside no sólo en continuar ejerciendo estas funciones, sino también en constituirse como entornos virtuales y digitales, es decir, como contextos educativos informales, ampliando su oferta pedagógica. Barron y Bell (2015) subrayan la importancia de fusionar estos contextos, creando entornos híbridos de aprendizajes que propicien conexiones entre 
hogares, escuela y comunidades, con el objetivo de fortalecer estas experiencias de aprendizaje.

Ahora bien, ¿cómo pueden establecerse vínculos entre estos contextos de aprendizaje?

Reynoso-Haynes (2000) establece que la colaboración entre las escuelas y los museos sirve para incrementar las oportunidades para aprender ciencia tanto para los maestros como para los estudiantes, ya que los MC proporcionan un amplio número de oportunidades para diferentes formas y estrategias de enseñanza y aprendizaje. Sin embargo, se ha visto que esto difícilmente sucede a menos que la visita al museo esté conectada con el currículum del aula, por lo que la implicación de los profesores en la preparación de la visita es imprescindible (Martins de Souza, Bonifácio y Rodrigues 2017; Guisasola y Morentín 2010). Sánchez-Mora y Luz-Ramírez (2016) sostienen que para aproximar a los docentes a lo que podría considerarse una visita exitosa, es esencial diseñar dicha visita. Las autoras afirman que esto evita que los estudiantes se enfrenten a ambientes y conceptos nuevos sin previa información y sensibilización; además, tal preparación de la visita sostiene como objetivo brindar a los estudiantes el dominio de su propio aprendizaje, es decir, libertad de acción.

Alderoqui y Linares (2005) agregan aportes interesantes para entender la sociedad entre las escuelas y los museos. Las autoras sostienen que educar en los museos implica alcanzar a los visitantes para que la experiencia del museo empiece antes de que lleguen; construir una motivación positiva para la visita; asegurar que las expectativas de los visitantes se encuadren con lo que se exhibe, para poder construir conexiones entre las experiencias del museo y sus vidas; incluir y valorar las interpretaciones de los visitantes respectos de las colecciones y la propuesta del museo; ofrecer oportunidades para que los visitantes puedan resolver problemas, formular hipótesis, clasificar, comparar elementos y fenómenos, verificar la veracidad o falsedad de una información, emitir juicios críticos y agregar emoción a la experiencia de aprendizaje.

En el caso de los museos virtuales, Elisondo y Melgar (2015) argumentan que éstos son espacios interesantes porque permiten ampliar el límite de acceso al conocimiento, así, cualquier persona, desde cualquier lugar del mundo, puede conocer aspectos culturales y naturales de otros países. De este modo, los museos virtuales se constituyen en escenarios atractivos para la educación permanente. Las autoras señalan que entre los aspectos potencialmente fructíferos de los museos virtuales se encuentran el acceso a la información y los contenidos que brinda el museo. En lo que respecta al acceso a la información, los museos virtuales posibilitan la aproximación a productos de la creación humana, la entrada gratuita de cualquier persona y permiten trascender las limitaciones físicas del espacio y del tiempo. En relación con los contenidos que se ofrecen, las autoras destacan la existencia de museos virtuales vinculados con diferentes ramas del conocimiento y la posibilidad de emplear distintos recursos tecnológicos, que incluyen simulaciones, acceso a teleconferencias, sistemas de discusión y colaboración, entre otras cuestiones.

En este marco, los museos virtuales están experimentando una transición desde la web 2.0 a la web 3.0, la cual busca la concreción de entornos colaborativos, centrados en la participación y la generación de contenido por parte de los usuarios (Asensio, Fernández Betancor, Cuenca, Fontal y Ibáñez Etxeberria 2012). Asimismo, se propone el desarrollo de una narrativa hipermedia, la cual se basa en estructuras interactivas, informativas, persuasivas y hasta dramáticas (Barinaga López, Moreno Sánchez y Navarro Newball 2017).

Sin embargo, se considera que los museos virtuales tienen ciertas limitaciones, entre las que se pueden mencionar las siguientes: la necesidad de contar con ciertos conocimientos y habilidades referidas al uso de las TIC; el bagaje cultural e intelectual necesario para participar 
de las experiencias educativas propuestas por los museos virtuales y digitales como posible obstáculo para el acceso democrático al patrimonio expuesto; la necesidad de conexión a Internet; la imposibilidad de recrear la experiencia sensorial que implica la visita a un museo físico, lo cual se ve agravado por la escasa calidad de imagen y sonido de algunos museos virtuales y el escaso desarrollo de narrativa hipermedia -la cual se ha logrado con mayor contundencia en los museos físicos (Melgar, Gómez y Donolo 2009; Barinaga López, Moreno Sánchez y Navarro Newball 2017).

En consideración de estas ventajas y limitantes y, en consonancia a lo propuesto para la organización de la visita a museos físicos, Melgar y Donolo (2011) delinean algunas sugerencias relevantes para potenciar el trabajo en estos contextos de aprendizaje. En este marco, si los docentes desean integrar los museos virtuales a sus clases, resulta fundamental explorar los escenarios virtuales de antemano, visitar más de una vez dichos sitios con los estudiantes y utilizar la visita como espacio para observar cómo aprenden los alumnos.

Así, resulta esencial realizar una revisión sistemática de los MC virtuales iberoamericanos en español disponibles en Internet y relevar sus potencialidades para la enseñanza y el aprendizaje de las ciencias naturales. Se considera que el estudio puede ser relevante tanto para docentes interesados en aproximarse a estos escenarios de aprendizaje, como para los educadores de los museos. En la próxima sección se detalla la metodología utilizada para llevar a cabo este estudio.

\section{Metodología}

Para la selección de los museos virtuales de ciencias, se optó por definir los siguientes criterios: que los mismos se encuentren integrados en el Registro de Museos Iberoamericanos (RMI) caracterizados como "Museo" bajo el filtro tipología de Institución Museal y como "Ciencia y Tecnología" y "Ciencias Naturales/Historia Natural" en tipo de colecciones. Esta elección se complementó con la búsqueda de museos a través de tres buscadores de Internet. Otro criterio fue el descarte de los folletos digitales (microsites), entendidos éstos como aquellos enfocados solamente a proporcionar datos útiles que inciten la visita física al museo (por ejemplo, programa museístico, horarios de apertura, tarifas, información de contacto y/o algunas fotos del interior y exterior del edificio) (Piacente 1996). Además, se tuvo en cuenta que los museos virtuales se presentaran en idioma español.

El tamaño de la muestra final se constituyó con un total de 28 museos virtuales de ciencias, entre ellos cuatro pertenecientes a Argentina, uno a Chile, cinco a México, uno a Colombia y dieciséis a España (Anexo 1), de los cuales 21 son de entidad pública y 7 de entidad privada. La gran mayoría de las páginas web de los MC fueron folletos digitales, quedando así más de 390 museos fuera del análisis.

El estudio se realizó a través de un método de análisis de contenido con carácter descriptivo y metodología cuali-cuantitativa. Este método se define como un conjunto de técnicas para estudiar y analizar la comunicación, tendiente a obtener indicadores por procedimientos sistemáticos de descripción del contenido de los mensajes, permitiendo hacer inferencias válidas y confiables de datos respecto a su contexto (Bardin, 1986). Tiene una orientación fundamentalmente empírica, exploratoria y de finalidad predictiva, otorgando conocimientos, representaciones de fenómenos reales y una guía práctica para la acción (Krippendorff, 1990).

Las categorías de análisis se construyeron a partir de aquellas validadas por otros autores: contenido multimedia, nivel de procesamiento cognitivo que exigen las actividades (GarciaRomano 2011; Vázquez, Jakob, Rosales y Pelizza 2006); información al usuario y facilidad de uso, grado de realismo (Martínez, Mir y Garcia-Romano 2017; Piassentini y Occelli 2012); 
evaluación (Piassentini y Occelli 2012); acompañamiento de guía didáctica (Ouariachi, OlveraLobo y Gutiérrez-Pérez 2017); tipología de los museo (Piacente 1996; Sabbatini 2003); tipos de contenidos y visión de ciencia que promueve el museo virtual (Audisio 2010); y en base a aspectos emergentes que surgieron de una exploración inicial de los museos virtuales. En el caso de la categoría tipología del museo se consideró adecuado lo propuesto por Piacente (1996) y Sabbatini (2003) debido a que la totalidad de los museos virtuales analizados cuentan con la existencia de un museo físico.

La validez y fiabilidad del estudio se garantizó mediante un juicio de expertos y con el acuerdo entre las autoras del trabajo para analizar los museos virtuales con las mismas categorías (Hernández-Sampieri, Fernández-Collado y Baptista 2010). En el caso particular del juicio de expertos, el instrumento con las categorías de análisis fue revisado por una especialista en Didáctica de las Ciencias, dos guías museales y 11 profesores de ciencias en ejercicio. A partir de sus sugerencias el instrumento fue reestructurado y se concretó su versión final (Ruiz 2002).

\section{Instrumento de análisis construido}

En la Tabla 1 se detalla el instrumento de análisis de los museos virtuales de ciencias con las dimensiones, categorías y subcategorías correspondientes.

Tabla 1. Instrumento de análisis construido en el que se describen las dimensiones "TIC", "Didáctica" y "Ciencia".

1. Dimensión "TIC"

1.1. Tipología de los museos

1.1.1. Museo en el mundo virtual: Proporciona información útil que incita a la visita física al museo. Es la proyección, con la máxima fidelidad, del museo físico en el mundo virtual. Presenta planos del museo físico para consultar colecciones. Se destaca la función de divulgación científica.

1.1.2. Museo verdaderamente interactivo: Guarda relación con el museo físico pero se reinventan o añaden elementos, introduciendo al visitante en actividades interactivas. La división entre el museo físico y el museo online permite que el entorno web tenga personalidad y funcionalidad propia. El usuario es el enfoque para la conceptualización del diseño del escenario, donde en función de los objetivos del museo pueden incluirse distintos elementos y grados de interacción entre el museo y el visitante.

1.2. Contenido multimedia: se refiere a la presencia de imágenes, vídeos y/o de audios.

1.2.1.Presencia.

1.2.2. Ausencia.

1.3. Información al usuario y facilidad de uso.

1.3.1. Alto: Presenta mapa de navegación, posibilidad de conexión a un buscador, objetivos del museo, información variada. Se encuentran rápidamente los contenidos buscados y la forma de utilizarlos (interfaz) es intuitiva. Propuesta de enlaces que funcionan correctamente.

1.3.2. Medio: Presenta dos aspectos menos que lo propuesto para el punto 1.3.1.

1.3.3. Bajo: Presenta cinco aspectos menos que lo propuesto para el punto 1.3.1.

1.4. Grado de realismo.

1.4.1. Alto: Imágenes en tres dimensiones. Posibilidad de manipulación sobre los objetos que se presentan, con una alta definición, parecido al escenario real.

1.4.2. Medio: Imágenes en dos dimensiones. Realismo limitado pero alta definición de las imágenes.

1.4.3. Bajo: Imágenes en dos dimensiones. Imágenes de baja definición o como representaciones gráficas. 
1.5. Conectividad con redes sociales: Se refiere al enlace que poseen las páginas web de los museos con redes sociales, como por ejemplo Facebook, Twitter y YouTube, y a las características de las publicaciones en ellas.

1.5.1. Alto: Presenta enlace con tres o más redes sociales.

1.5.2. Medio: Presenta enlace con dos redes sociales.

1.5.3. Bajo: Presenta conectividad con al menos una red social.

1.5.4 Nula: Ausencia de conectividad con redes sociales.

2. Dimensión "Didáctica"

2.1. Nivel de procesamiento cognitivo que exigen las actividades.

2.1.1. Alto: Explorar e indagar.

2.1.2. Bajo: Memorizar y reproducir.

2.1.3. Nulo: Ausencia de actividades.

2.2. Evaluación: Grado de retroalimentación sobre los avances de los usuarios durante el recorrido por el museo virtual. Posibilidad de autoevaluación.

2.2.1. Alto: Indica errores. Devolución con fundamento. Promueve reflexión metacognitiva.

2.2.2. Medio: Indica errores pero no ofrece posibilidad de reflexión metacognitiva.

2.2.3. Bajo: No indica errores.

2.2.4. Nulo: No presenta actividades evaluativas.

2.3. Tipos de contenidos que promueve el museo virtual: conceptuales, procedimentales y actitudinales.

2.3.1. Presencia contenidos conceptuales.

2.3.2. Ausencia contenidos conceptuales.

2.3.3. Presencia contenidos procedimentales.

2.3.4. Ausencia contenidos procedimentales.

2.3.5. Presencia contenidos actitudinales.

2.3.6. Ausencia contenidos actitudinales.

2.4. Acompañamiento de guía didáctica: documento o enlace a información destinada a los docentes con consejos y sugerencias para implementarlo en el aula.

2.4.1. Presencia.

2.4.2. Ausencia.

3. Dimensión "Ciencia"

3.1. Visión de ciencia que promueve.

3.1.1. Ciencia Objetiva: el museo muestra un lenguaje científico y una ciencia no mediada por las ideas de las personas.

3.1.2. Ciencia Aplicada: el museo concibe a la ciencia como mejoradora de la calidad de vida propiciando la participación de las personas. Se la sitúa en un contexto social, explicitado por las aplicaciones de investigaciones científicas al ámbito cotidiano.

3.2. Perspectiva histórica de la ciencia: Refiere a si la presentación del contenido científico tiene en cuenta el origen y el progreso de su construcción.

3.2.1. Presencia.

3.2.2. Ausencia

3.3. Investigación y divulgación.

3.3.1. Presencia de proyectos y/o artículos de investigación.

3.3.2. Presencia de proyectos y/o artículos de divulgación.

3.3.3. Presencia de proyectos y/o artículos de investigación y divulgación.

3.3.4. Ausencia de proyectos y/o artículos de investigación y divulgación. 


\section{Resultados y discusión}

\section{Análisis de los museos virtuales de ciencias}

El análisis arrojó en primer lugar que el $71 \%$ de los museos analizados pertenecían a la subcategoría museo en el mundo virtual, mostrando máxima fidelidad con el museo físico, y un $29 \%$ se ubicó en la subcategoría museo verdadermante interactivo. Estos datos permiten decir que son escasos los museos que están orientados a la interactividad, es decir, a promover acciones recíprocas entre el sitio y el usuario en tiempo real (Rost 2006). La baja interactividad registrada indicaría que este potencial no ha sido aprovechado por un gran número de los museos analizados.

Se destacó que la totalidad de los museos virtuales estudiados presentaron contenido multimedia, tal y como puede verse en la Figura 1, en la cual se observa la presencia de un audio que el usuario puede clickear para escuchar sonidos de aves y en la Figura 2, en la cual pueden visualizarse numerosas fotografías de distintos insectos para que el usuario identifique. Como señala Marquès-Graells (2000), las características multimediales capturan el interés de los usuarios, proporcionan información, posibilitan un trabajo individual y también en grupo, $\mathrm{y}$, en este caso, orientan el aprendizaje y el pensamiento en torno a los contenidos de ciencias naturales.

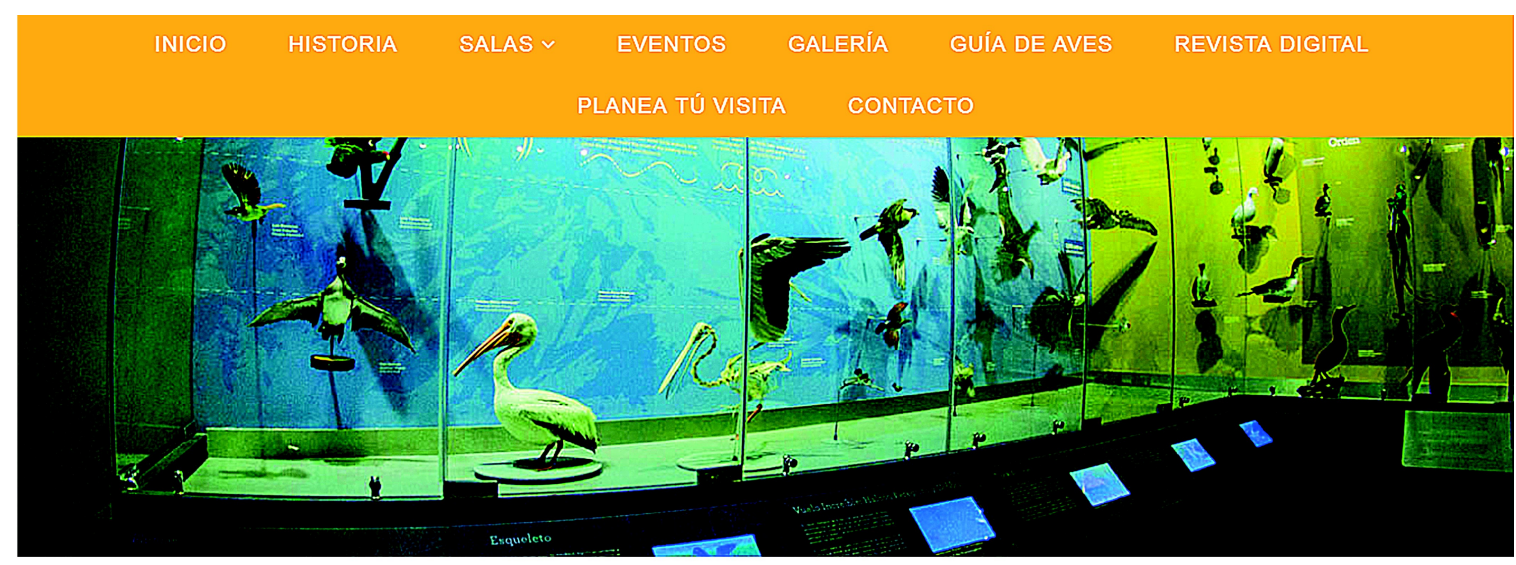

Escucha la cápsula radiofónica AVE-CITA

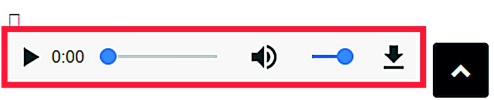

Figura 1. Imagen del “Museo de las Aves de México”. Rescatado de https://musave.org/ el día 20/10/2017.

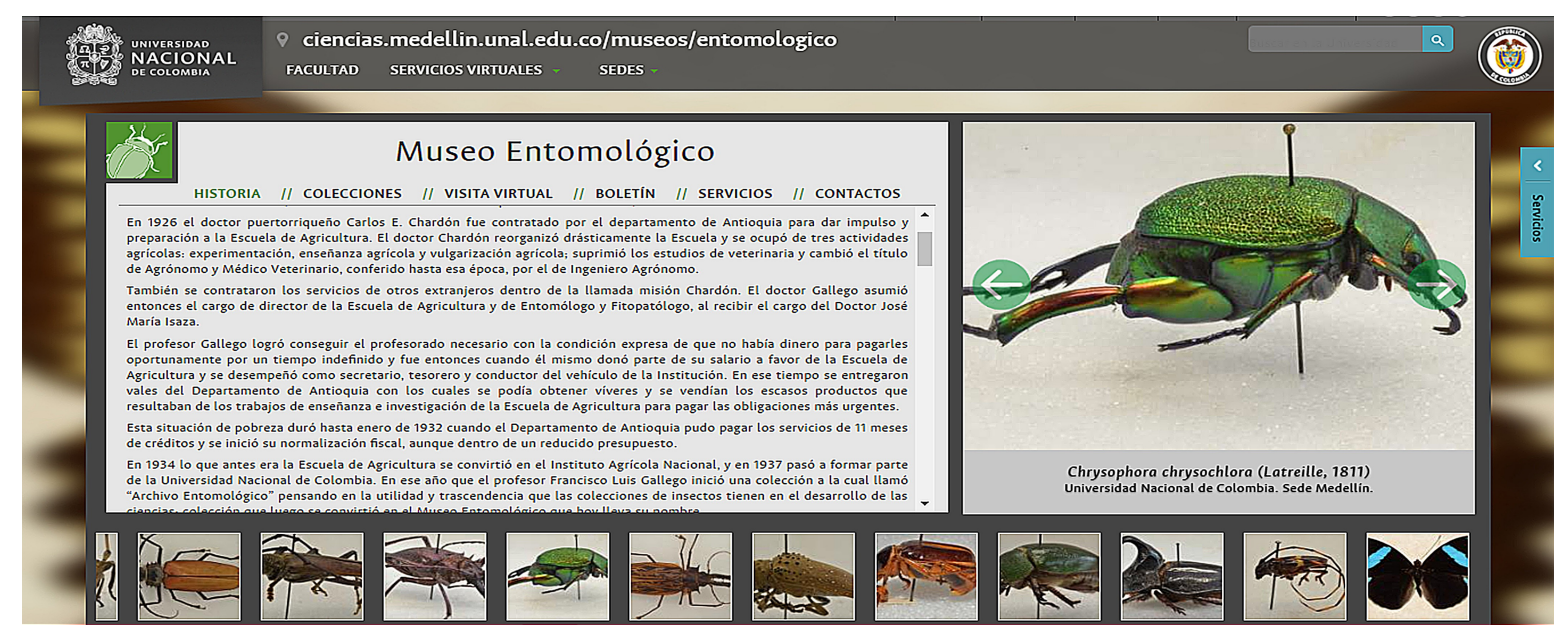

Figura 2. Imagen del "Museo Entomológico Francisco Luis Gallego" de Colombia. Rescatado de http://ciencias.medellin.unal.edu.co/museos/entomologico/ el día 20/10/2017. 
Además, el análisis mostró que un $82 \%$ de los museos virtuales presentó un nivel alto en cuanto a la categoría información al usuario y facilidad de uso, mientras que sólo un 18\% evidenció nivel medio. Sin embargo, al profundizar en otras categorías de análisis, se resalta que predominan imágenes en dos dimensiones, y que sólo el $21 \%$ posee imágenes en tres dimensiones y un alto grado de definición como puede observarse en las imágenes 3D de la Figura 3. Se considera que mientras mayor sea el grado de realismo en los museos virtuales, estos resultarán más atractivos y motivadores para los usuarios.

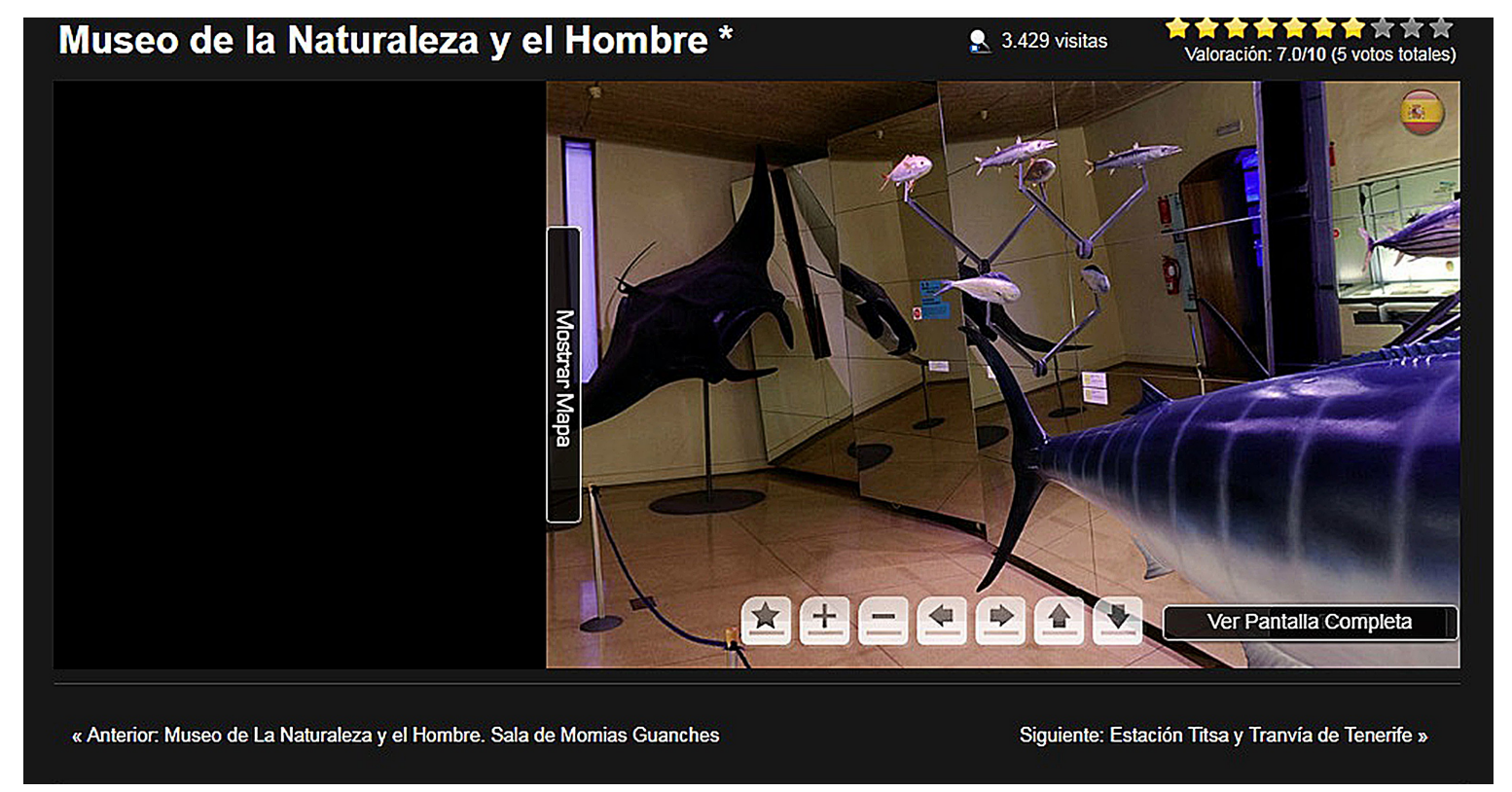

Figura 3. Imagen del "Museo de Naturaleza y Arqueología (MUNA)" de España. Rescatado de http://www.museosdetenerife.org/mnh-museo-de-la-naturaleza-y-el-hombre el día 20/10/2017.

En cuanto a la conectividad con redes sociales, se encontró que el 54\% de los museos presentaba un nivel alto, manteniendo enlace con tres o más redes sociales, sólo el 4\% presentó conectividad con dos redes sociales, el 21\% de las páginas se enlazó sólo con una red social (en todos los casos con Facebook), y otro 21\% no presentó ninguna conectividad. Al indagar las características de las publicaciones que se realizan en las redes sociales, se encontró que la mayoría de ellas presentó las mismas publicaciones que la página web como así también otras distintas (promociones de eventos, programas de divulgación científica, etc.) con un mínimo de 5 publicaciones semanales. Mientras que el resto de las publicaciones tuvo una frecuencia de publicación menor. Se destacó entonces, la inclusión de las redes sociales como herramientas 3.0 en la gestión de comunicación del museo (Abad, de la Casa y Lorenzo 2010), como parte de una estrategia más abierta y participativa, tal como se dijo en la introducción, en respuesta a la demanda de la sociedad actual. En este sentido, Merín (2015), afirma que las redes sociales son vías de comunicación sumamente accesibles, en las cuales se encuentran múltiples emisores y receptores. Así, como sostiene esta autora, la conectividad con redes sociales, al ceder el protagonismo al usuario, provoca que éste se involucre en el proyecto museístico, se identifique con sus valores y se comprometa con la misión de la institución. En esta línea se piensa que resultaría interesante, debido a sus ventajas, reforzar cada vez más la interacción entre las redes sociales y MC.

En relación con la dimensión "Didáctica", en lo que respecta al nivel de procesamiento cognitivo que exigen las actividades, se evidenció que la mayoría de los museos no presentaban actividades (48\%), lo cual demostró que el potencial de ofrecer estos recursos para personas que no tienen la posibilidad de ir al museo físico no es totalmente aprovechado. 
En aquellos sitios que sí poseían actividades, éstas se caracterizaron por apuntar a la memorización y reproducción, mientras que sólo un 15\% requirió explorar e indagar. Una de éstas se ejemplifica en la actividad de la Figura 4, en la cual se presentaba al usuario un ecosistema que frente a las acciones antropogénicas podía avanzar hacia dos escenarios distintos. Esta actividad exigía indicar, describir y analizar, conduciendo a la exploración e indagación. Según la RNC (2000), la indagación es central para el aprendizaje de las ciencias, ya que los estudiantes describen objetos y fenómenos, elaboran interrogantes, construyen explicaciones, las sitúan en relación con lo que se sabe del conocimiento científico, y comunican sus ideas a otros. Los alumnos identifican sus hipótesis, utilizan el pensamiento crítico y lógico, y consideran explicaciones alternativas. De esta manera, desarrollan activamente su comprensión de la ciencia al combinar el conocimiento científico con las habilidades de razonamiento y pensamiento. Esto manifiesta la importancia de la elección del museo por parte de los docentes para que estos recursos tecnológicos propicien la construcción del conocimiento sobre ciencias.

AB2.1 En el futuro próximo, el ecosistema de las Lagunas de Ruidera
puede evolucionar de dos formas muy diferentes, las cuales dependen de
las acciones de los seres humanos sobre él.

En la sala que estás visitando, puedes observar estas mismas figuras que intentan representar los dos futuros posibles. Debajo de cada una de ellas:

A. Indica los principales componentes, naturales y artificiales, del paisaje.

B. Describe lo que ha ocurrido en cada caso.

C. Tras su análisis, ¿a qué conclusión llegas?
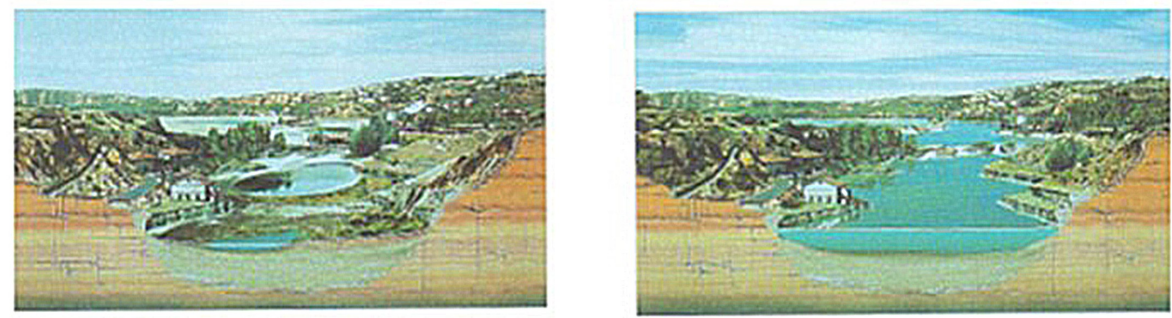

$\mid$

Conclusión:

Figura 4. Imagen del "Museo de Naturaleza y Arqueología (MUNA)" de España. Rescatado de https://www.museosdetenerife.org/muna-museo-de-naturaleza-y-arqueologia el día 20/10/2017.

En referencia a las actividades evaluativas, el $86 \%$ de los museos virtuales se distinguió por no presentar estas actividades, el 11\% no indicó errores en las resoluciones de las actividades y sólo el 3\% señaló errores, encontrándose ausentes las devoluciones con fundamento y promulgación de la reflexión metacognitiva. Debido a estos resultados, se considera necesario que se proporcione información sobre lo que el usuario está aprendiendo y se brinden oportunidades de autoevaluación, para así favorecer la metacognición acerca del proceso de aprendizaje. Ante la carencia de este tipo de evaluación, se propone como alternativa que los 
docentes acompañen la utilización del contexto de aprendizaje con guías de actividades evaluativas que promuevan que los alumnos reflexionen sobre los contenidos en juego.

Con respecto a los tipos de contenidos que promueven los museos virtuales, se observó que un $93 \%$ fomentó los del tipo conceptual, un $36 \%$ los de tipo procedimental y un $25 \%$ los de tipo actitudinal. Se considera que la presencia de estos tres tipos de contenidos resulta fundamental ya que, como señalan Vilches y Furió (1999), incluir contenidos conceptuales supone conocimientos científicos necesarios para que los alumnos puedan desenvolverse en un mundo progresivamente embebido por el desarrollo científico; incluir contenidos procedimentales permite aprender lo que es la ciencia y cómo trabaja y, por último, contemplar contenidos actitudinales genera en el alumnado interés por la ciencia. En concordancia con los resultados de Audisio (2010), se encontró que los contenidos conceptuales estaban ampliamente representados, resultando escasos aquellos referidos a lo procedimental y actitudinal. Al respecto, es interesante considerar que cuanto mayor sean las posibilidades de interaccionar con museos, el alumno tendrá mayores posibilidades de desarrollar habilidades procedimentales, y que la carencia de contenidos actitudinales podría conducir al detrimento del desarrollo personal, la responsabilidad, la socialización y las actitudes positivas hacia la ciencia, cuestiones que eventualmente podrían contribuir a estimular vocaciones científicas futuras (Vázquez-Alonso y Manassero-Mas 2007).

También se encontró para la dimensión Didáctica que el 46\% de los museos virtuales contó con la presencia de guías didácticas para el docente con recomendaciones para facilitar su inclusión en el aula, mientras que el 54\% exhibió ausencia de las mismas. Se resalta como aspecto contradictorio que más de la mitad de los museos virtuales no posee este recurso importante para ser utilizado en el aula, entendiéndolo según Melgar, Gómez y Donolo, (2009) como una externalización de las acciones cognitivas llevadas a cabo en el museo para facilitar el acceso y construcción de los conocimientos museísticos. En este sentido, los autores resaltan que la función esencial de toda actividad cultural colectiva es elaborar obras, que logren existencia propia.

Respecto a la dimensión "Ciencia", el 86\% de los museos virtuales presentó una visión de ciencia objetiva, mientras que el 14\% mostró una visión de ciencia aplicada. Frente a esta situación, se destaca la predominancia de un realismo pragmático que considera a la ciencia con la tarea de interpretar el mundo con determinadas ideas y explicar las decisiones científicas a partir de los criterios propios de los investigadores y no de principios racionales de carácter general (Quintanilla-Gatica 2000), de esta forma, la sociedad no adquiere un papel protagónico en la reflexión de la construcción científica del conocimiento tal como merecería. Esta situación es similar a la encontrada por Lau y Sikorski (2018) en la que se señala que los aspectos epistémicos (la incertidumbre, el sustento de afirmaciones con evidencias, etc.) suelen ser los más relegados en el contexto de los museos.

Se observó, además, un gran porcentaje de museos con ausencia de perspectiva histórica, centrados en un momento concreto de la historia de la comunidad científica, sin carácter evolutivo (Quintanilla-Gatica 2000), ya que sólo el 29\% contempló el contenido científico teniendo en cuenta el origen y el progreso de su construcción. Se sostiene que sería interesante progresar hacia museos virtuales de ciencias que contemplen los elementos del contexto de descubrimiento de la ciencia para proporcionar a los usuarios en general, pero sobre todo a docentes y alumnos, situaciones de referencia para que, al introducir nuevas analogías, o variables, puedan evolucionar hacia modelos o teorías más complejas (Jiménez-Aleixandre y Sanmartí 1997) y no ignorar el contexto de su emergencia y, en consecuencia, deshistorizarlo (Develay 1992). 
Por último, el $40 \%$ de los museos virtuales analizados presentan proyectos y/o artículos de investigación y divulgación, un porcentaje bajo muestra solo proyectos y/o artículos de investigación (14\%) o de divulgación (14\%), y el resto $(32 \%)$ ausencia de los mismos. Tal y como se mencionó en el inicio, la presencia de este tipo de propuestas contribuye a generar una sociedad más informada y por lo tanto, más crítica y reflexiva (Segarra, Gadea, Vilches y Gil-Pérez 2017; Armesto-Ramón, Martínez-Losada y García-Barros 2005 y Reynoso-Haynes 2000). Al respecto, Estrada (1992) destaca que la divulgación de la ciencia implica poner al alcance del público los elementos necesarios para que puedan integrar el conocimiento científico a la cultura. Por otro lado, cuando los museos virtuales dan a conocer sus proyectos de investigación, los docentes pueden considerar esta información e incorporarla en sus actividades (Melgar, Gómez y Donolo 2009). En este marco, resulta preciado difundir las habilidades, capacidades y destrezas que los científicos han desarrollado (plantear problemas, buscar soluciones, confrontar ideas con colegas, trabajar en equipo) para que la sociedad pueda adquirirlas. En el mismo sentido, la existencia de proyectos de divulgación y la posibilidad de encontrar diferentes fuentes informativas en el mismo museo, contribuyen a compartir y comunicar experiencias personales y de equipos de trabajo, acerca de la ciencia, la tecnología y el ambiente y así se aumenta la visión de mundo y se favorece la construcción de conocimiento científico (Elisondo y Melgar 2015; Melgar, Gómez y Donolo 2009).

En los Anexos 2, 3 y 4 se ofrece un panorama detallado de las dimensiones analizadas en los 28 museos virtuales estudiados.

\section{Conclusiones}

El presente trabajo pretende constituirse en un aporte para los docentes del área interesados en pensar experiencias educativas diferentes, integrando museos virtuales en sus clases y planificando actividades que conduzcan a un contexto social y cultural más amplio. Por otro lado, se sostiene que las categorías utilizadas pueden servir de referencia a profesores e investigadores para analizar y escoger otras herramientas TIC posibles de ser implementadas en el aula. Por último, la investigación brinda información valiosa a autoridades, educadores y conservadores de los museos para lograr mejoras en ellos.

A partir de los resultados obtenidos se puede concluir que la mayoría de los museos virtuales analizados evidenciaron un avance importante en la dimensión "TIC". Sin embargo, el desafío esencial se constituye en ir en busca de un aumento de la interactividad para el usuario, a fin de aprovechar aún más este potencial. Con respecto a las dimensiones "Didáctica" y "Ciencia", se enfatiza la necesidad de profundizar esfuerzos para que los museos virtuales aporten actividades y/o recursos didácticos que aborden tanto contenidos conceptuales como procedimentales y actitudinales, de manera tal que se brinden oportunidades para aquellas personas que no pueden concurrir físicamente al museo y se aporte una visión de ciencia aplicada que contemple la historicidad del conocimiento.

En lo que respecta a la potencialidad para la enseñanza y el aprendizaje de las ciencias naturales en marco del vínculo escuelas-museos, se recomienda a los docentes seleccionar aquellos escenarios que posean características superadoras (que posean los valores más completos o altos en las dimensiones de análisis estudiadas), siempre desde una perspectiva situada que contemple los objetivos propuestos para sus clases. Tener en cuenta las diferentes dimensiones de análisis abre la posibilidad a analizar si los museos ofrecen oportunidades variadas para aprender, ya sea porque proponen recursos tecnológicos potentes (juegos, simulaciones, etc.), porque enlazan con información científica actualizada, etc.

En lo que atañe al plano de la conexión con redes sociales, el hecho de que los museos estén avanzando cada vez más en esta cuestión abre paso a nuevas interacciones entre docentes, 
alumnos y educadores de los museos. Así, los estudiantes pueden realizar comentarios y preguntas acordes a sus intereses y a los contenidos que se estén desarrollando en las clases de ciencias. Este aspecto aumenta las posibilidades de contacto y trabajo colaborativo entre estudiantes de una misma escuela, con otras escuelas y con el personal especializado de los museos.

Finalmente, se considera oportuno remarcar que si bien los museos virtuales permiten conectar con lugares y épocas diferentes a los de los visitantes, en el marco de las escuelas es importante potenciar esa oportunidad a través de la creación de propuestas didácticas específicas. Así, los docentes tienen que ser artífices en la construcción de actividades que aproximen a los estudiantes a experiencias de aprendizaje novedosas a través del museo y, en un punto, trascender y transformar la propuesta propia del museo que está pensada para un público amplio. En otras palabras, los profesores tienen que pensar cuál es el potencial específico que aporta un determinado museo a su trabajo en el aula de ciencias.

\section{Agradecimientos}

Las autoras agradecen a las entidades financiadoras (SECYT de la Universidad Nacional de Córdoba y Consejo Nacional de Investigaciones Científicas y Técnicas, CONICET) y a las expertas del área y profesores en ejercicio que revisaron el instrumento de investigación.

\section{Referencias}

Abad M. V., de la Casa J. M. H., Lorenzo F. C. (2010) La Comunicación corporativa de los museos en Espanã a través de la comunicacion 3.0: cuatro años de la evolución comunicativa en la Red, en II Congreso internacional comunicación (Vol. 3).

Alderoqui S., Linares M.C. (2005) El libro de visitantes del museo de las escuelas: un diálogo entre narrativas. Enseñanza de las Ciencias Sociales, 4, 117-128.

Alegret Tejero J.L., Martí Llambrich M. (2003) Valoración patrimonial del sector pesquero. El caso del Museu de la Pesca de Palamós. Zainak. 25, 427-442.

Armesto-Ramón F., Martínez-Losada C., García-Barros S. (2005) Museos como respuesta a las necesidades de formación a la ciudadanía. Alambique, 12(43), 49-56.

Asensio M., Fernández Betancor H., Cuenca J.M., Fontal O., Ibáñez Etxeberria A. (2012) Una reflexión sobre WEBs, Museos y Turismo Cultural a partir de un estudio cualitativo de indicadores expertos, en Asensio M., Ibañez A., Caldera P., Asenjo E., Castro E. (Eds.), SLAM. Series Iberoamericanas de Museología. Vol. 3. Madrid: Universidad Autónoma de Madrid.

Audisio C. (2010) Las páginas web de museos de ciencias latinoamericanos como herramientas educativas: caracterización y propuestas de aplicación, en M. C., Ortiz (Compil.), IX Jornadas Nacionales, IV Jornada Internacional de Enseñanza de la Biología. Simposio dirigido por Asociación de Docentes de Ciencias Biológicas de la Argentina. Tucumán, Argentina.

Banqué N., Calafell G., Bonil J. (2013) Construyendo el perfil competencial de los educadores de museos y centros de ciencia, pp. 266-269 en Bonil J., Marbà A., Márquez C. (Eds), IX Congreso Internacional sobre Investigación en Didáctica de las Ciencias. Girona: Universidad de Girona.

Bardin L. (1986) El análisis de contenido. Madrid: Ediciones Akal.

Barinaga Lopez B., Moreno Sanchez I., Navarro Newball A.A. (2017) La narrativa hipermedia en el museo. El presente del futuro. Obra digital, 12, 101-121. 
Barron B., Bell P. (2015) Learning environments in and out of school, pp. 323- 336 en Corno L., Anderman E. (Eds.), Handbook of Educational Psychology, Third Edition. New York: Routledge: Taylor \& Francis.

Becky O. (1998) Virtual Science Museums as Learning Environments: Interaction for Education. Informal Learning Review, 33, 8-13.

Bowen J. P., Bennett J., Johnson J. (1998) Virtual visits to virtual museums, en Bearman D., Trant J. (Eds.), Museums and the Web. Pittsburgh, PA: Archives \& Museum Informatics

Ceballos-Aranda M., Vílchez-López J.E. (2017) Visitas de escolares de educación primaria a museos de ciencias. Análisis preliminar sobre sus percepciones. Enseñanza de las ciencias: revista de investigación y experiencias didácticas, número extra, 1525-1530.

Cebrián de la Serna M., Gallego-Arrufat M.J. (2011) Procesos educativos con TIC en la sociedad del conocimiento. Madrid: Pirámide.

Crowley K., Pierroux.P. Knutson, K. (2014) Informal Learning in Museums, pp.461-478 en Sawyer R.K.(Ed.), The Cambridge Handbook of the Learning Sciences. New York: Cambridge University Press.

Cuenca J.M., Wamba A.M, Aguaded J.S (2006) Las actividades prácticas en museos de ciencias y centros de interpretación ¿Cómo orientarlas desde una perspectiva holística? Alambique, 47, 74-81.

Delgado-Buscalioni A. (2009) Rutas por museos y colecciones de Paleontología. Madrid: Instituto Geológico y Minero de España.

Develay M. (1992) De l'apprentissage à l'enseignement. Paris: ESF éditeur.

DeWitt J., Hohenstein J. (2010) Supporting student learning: A comparison of student discusion in museums and classrooms. Visitor Studies, 13(1), 41-66.

Echeverría J. (2008) Apropiación social de las tecnologías de la información y la comunicación. Revista CTS, 4(10), 171-182.

Elisondo R., Melgar M.F. (2015) Museos y la Internet: contextos para la innovación. Innovación educativa (México, DF), 15(68), 17-32.

Estepa J. (2013) La educación patrimonial en la escuela y el museo: investigación y experiencias. Huelva: Universidad de Huelva Publicaciones.

Estrada, L. (1992) La divulgación de la ciencia. Ciencias, 27, 69-76.

Garcia-Romano L. (2011) La lectura y la escritura en el ingreso universitario de carreras científicas y tecnológicas: un estudio sobre concepciones, expectativas y prácticas. Córdoba: Universidad Nacional de Córdoba.

González M., Gil-Pérez D., Vilches A. (2002) Los museos de ciencias como instrumentos de reflexión sobre los problemas del planeta. Tecné, Episteme y Didaxis, 12.

Guisasola J., Morentín M. (2010) Concepciones del profesorado sobre visitas escolares a museos de ciencias. Enseñanza de las Ciencias, 28(1), 127-140.

Hernández-Sampieri R., Fernández-Collado C., Baptista L.P. (2010) Metodología de la investigación. México: McGraw-Hill.

Jiménez-Aleixandre M.P., Sanmartí N. (1997) ¿Qué ciencia enseñar?: objetivos y contenidos en la educación secundaria, pp. 30-35 en Del Carmen L. (Ed.), La enseñanza y el aprendizaje de las ciencias de la naturaleza en la educación secundaria. Barcelona: Horsori. 
Krippendorff K., (1990) Metodología de análisis de contenido. Teoría y Práctica. Barcelona: Ediciones Paidós.

Lau M., Sikorski T. (2018) Dimensions of Science Promoted in Museum Experiences for Teachers. Journal of Science Teacher Education, 29(6), 1-22.

Lepouras G., Vassilakis C. (2004) Virtual museums for all: employing game technology for edutainment. Virtual Reality, 8(2), 96-106.

Marquéz-Graells P. (2000) Ventajas e inconvenientes del multimedia educativo. Departamento de Pedagogía Aplicada, Facultad de Educación. Universidad Autónoma de Barcelona.

Martínez G.F., Mir F., Garcia-Romano L. (2017) Caracterización de aplicaciones móviles para la enseñanza y el aprendizaje de la Anatomía Humana. Enseñanza de las ciencias: revista de investigación y experiencias didácticas, número extra, 1597-1603

Martins de Souza V., Bonifácio V., Rodrigues A.V. (2017) Etapas de planificação do pré, durante e pós-visita de estudo: uma revisão de literatura. Enseñanza de las ciencias: revista de investigación y experiencias didácticas, número extra, 1605-1610.

Melgar M.F., Donolo D.S. (2011) Salir del aula... Aprender de otros contextos. Patrimonio natural, museos e Internet. Revista Eureka sobre Enseñanza y Divulgación de las Ciencias, 8(3), 323-333

Melgar M. F., Gómez M.C., Donolo D. (2009) Los museos virtuales y digitales. Aportes desde una perspectiva psicoeduactiva. X Encuentro Internacional Virtual Educa Argentina. Organización de los Estados Iberoamericanos (OEI). Pontificia Universidad Católica Argentina. Del 9 al 13 de noviembre de 2009. Buenos Aires.

Merín C. (2015) Museos y redes sociales: de la difusión a la interacción. Barcelona: Ende comunicación.

Morentín M. (2013) Formación inicial del profesorado de primaria en visitas escolares a MYCC, pp. 2393-2397 en Bonil J., Marbà A., Márquez C. (Eds.), IX Congreso Internacional sobre Investigación en Didáctica de las Ciencias. Girona: Universidad de Girona.

Morentín M., Guisasola J. (2014) La visita a un museo de ciencias en la formación inicial del profesorado de Educación Primaria. Revista Eureka sobre Enseñanza y Divulgación de las Ciencias, 11 (3), 364-380

Müller K. (2002) Museums and virtuality. Curator: The Museum Journal, 45(1), 21-33.

Ouariachi T., Olvera Lobo M. D., Gutiérrez Pérez, J. (2017) Evaluación de juegos online para la enseñanza y aprendizaje del cambio climático. Enseñanza de las ciencias, 35(1), 193-214.

Piacente M. (1996) Surf's up: museums and the World Wide Web. Toronto: University of Toronto.

Piassentini M.J., Occelli M. (2012) Caracterización de Laboratorios Virtuales para la enseñanza de la Ingeniería Genética, en Memorias de las X Jornadas Nacionales y $V$ Congreso Internacional de Enseñanza de la Biología. Villa Giardino. Córdoba: Asociación de Docentes de Ciencias Biológicas de la Argentina.

Quintanilla-Gatica M.R. (2000) Bases epistemológicas y didácticas del curriculum en ciencias biológicas. Extracto de la Conferencia presentada en el Primer Seminario Taller en Didáctica de la Biología, Valparaíso.

Rábano I., Rodrigo A. (2001) El museo geominero: un recurso didáctico para la enseñanza de la paleontología. Enseñanza de las Ciencias de la Tierra, 9(2), 183-189. 
Rennie L.J., Johnston D.J. (2004) The nature of learning and its implications for research on learning from museums. Science Education, 88(S1), 4-16.

Reynoso-Haynes E. (2000) El museo de las ciencias: un apoyo a la enseñanza formal. México: Universidad Nacional Autónoma de México.

RNC. (2000) Inquiry And The National Cience Education Standards. Washington, D.C.: National Academy Press.

Roldán A.I., Ulloa D., Vargas L., Chura Z., Pacheco L.F. (2017) Comparación entre recorridos guiados tradicionales y recorridos guiados indagatorios en el Museo Nacional de Historia Natural, La Paz-Bolivia. Revista Eureka sobre Enseñanza y Divulgación de las Ciencias, 14(2).

Rost A. (2006) La interactividad en el periódico digital. Barcelona: Universitat Autònoma de Barcelona.

Ruiz C. (2002) Instrumentos de investigación educativa. Procedimientos para su diseño y validación. Barquisimeto, Venezuela: CIDEG.

Sabbatini M. (2003) Centros de ciencia y museos científicos virtuales: teoría y práctica . Education in the Knowledge Society (EKS), 4(1).

Sánchez-Mora M.D.C., de la Luz-Ramírez C. (2016) Efectos sobre el aprendizaje informal de la evolución biológica como resultado de la mediación museal. Revista Eureka sobre Enseñanza y Divulgación de las Ciencias, 13(2), 315-341.

Segarra A., Gadea I., Vilches A., Gil-Pérez D. (2017) Uso de los museos para contribuir a superar las visiones deformadas de la ciencia. Enseñanza de las ciencias: revista de investigación y experiencias didácticas, número extra, 3827-3832.

Segarra-Castelló A.S. (2009) Los museos de ciencias como instrumentos de alfabetización científica. Enseñanza de las ciencias: revista de investigación y experiencias didácticas, número extra, 223-226.

Soler M. (2014) Análisis del desarrollo de un proceso de innovación sobre el enfoque didáctico de un museo de ciencia. Enseñanza de las ciencias: revista de investigación y experiencias didácticas, 32(1), 287-288.

Trilla J., Gros B., López F., Martin M.J. (2003) La educación fuera de la escuela. Ámbitos no formales y educación social. Barcelona: Ariel.

UNESCO. (2004) Las tecnologías de la información y la comunicación en la formación docente. Guía de planificación. Montevideo: Trilce.

Varela Calvo C., Stengler E. (2004) Los Museos interactivos como recurso didáctico: El Museo de las Ciencias y el Cosmos. Revista Electrónica de Enseñanza de las Ciencias, 3(1), 32 47.

Vázquez-Alonso A., Manassero Mas M.A. (2007) Las actividades extraescolares relacionadas con la ciencia y la tecnología. Revista Electrónica de Investigación Educativa, 9(1), 1-22.

Vázquez A., Jakob I., Rosales P., Pelizza L. (2006) Consignas de escritura y procesos cognitivo-lingüísticos implicados. Un estudio en la universidad, en Primer Congreso Nacional Leer, Escribir y Hablar Hoy y Simposio: Enseñar a leer, escribir y hablar en todas las disciplinas de la educación superior. Tandil: Universidad Nacional del Centro de la Provincia de Buenos Aires. 
Viladot P. (2013) Análisis de las motivaciones, expectativas y objetivos de los docentes en sus visitas al museo de ciencias naturales de Barcelona, pp. 3711-3716 en Bonil J., Marbà A., Márquez C. (Eds.), IX Congreso Internacional sobre Investigación en Didáctica de las Ciencias (pp. 3711-3716). Girona: Universidad de Girona.

Vilches A., Furió C. (1999) Ciencia, Tecnología, Sociedad: Implicaciones en la Educación Científica para el Siglo XXI. Biblioteca Digital da OEI

Vilches-Peña A., Gil-Pérez D., González M., González E. (2006) La atención a la situación de emergencia planetaria en los museos de ciencias: El inicio de un cambio necesario. Ciencia \& Educaçao, 12(1), 39-56.

Yoon S.A., Elinich K., Wang J., Steinmeier C., Tucker S. (2012) Using augmented reality and knowledge-building scaffolds to improve learning in a science museum. International Journal of Computer-Supported Collaborative Learning, 7(4), 519-541. 
Anexo 1. Listado de los Museos a estudio, por países, con sus respectivas direcciones web

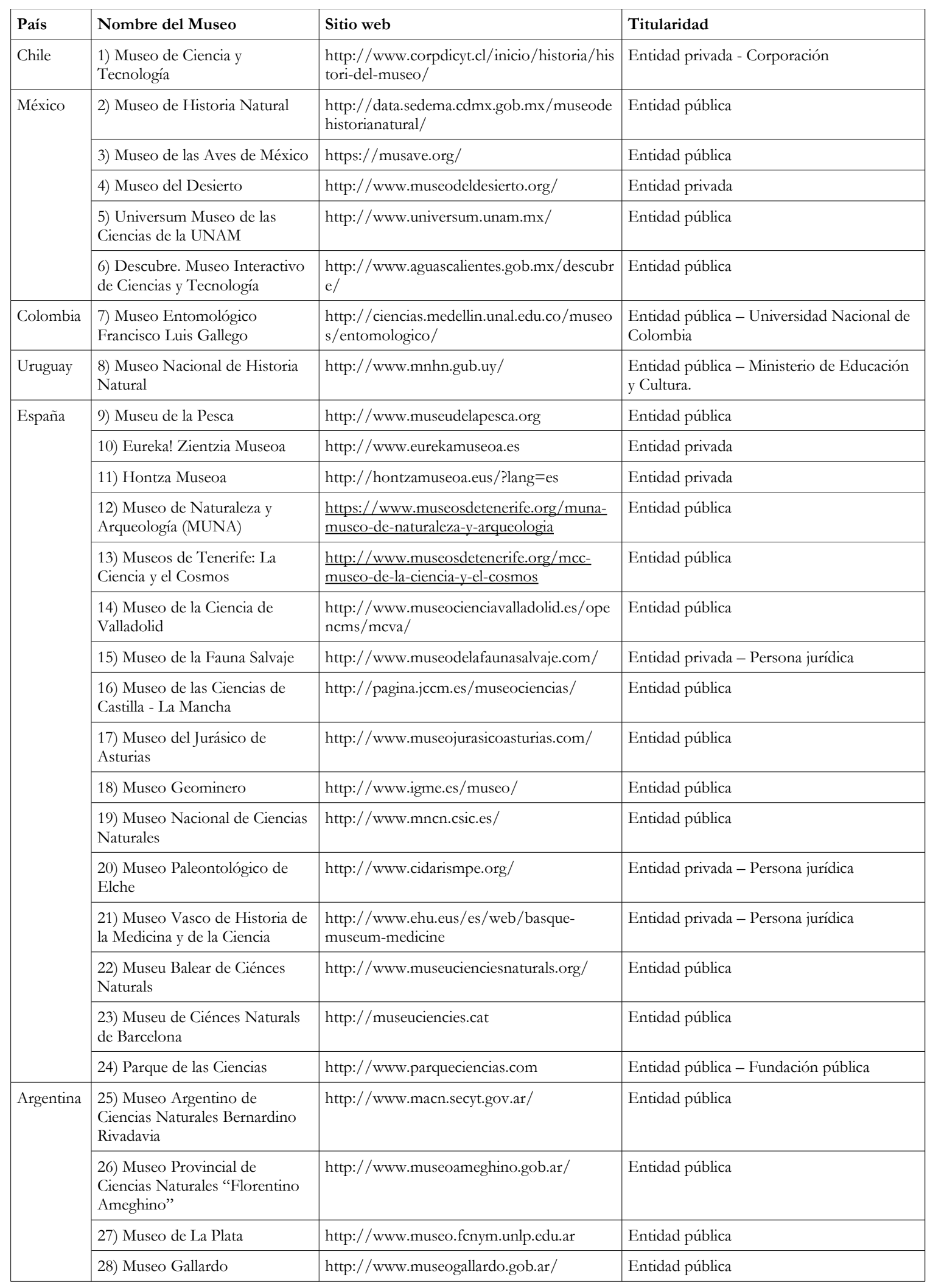


Anexo 2. Tabla de datos de la dimensión "TIC" de los museos virtuales de ciencias ( $\mathrm{P}=$ Presente, $\mathrm{A}=$ Ausente, $\mathrm{MV}=$ Museo en el mundo virtual, $\mathrm{MI}=$ Museo verdaderamente interactivo, $\mathrm{Al}=$ Alto, $\mathrm{M}=\mathrm{Medio}, \mathrm{B}=\mathrm{B}$ ajo, $\mathrm{N}=$ Nulo.).

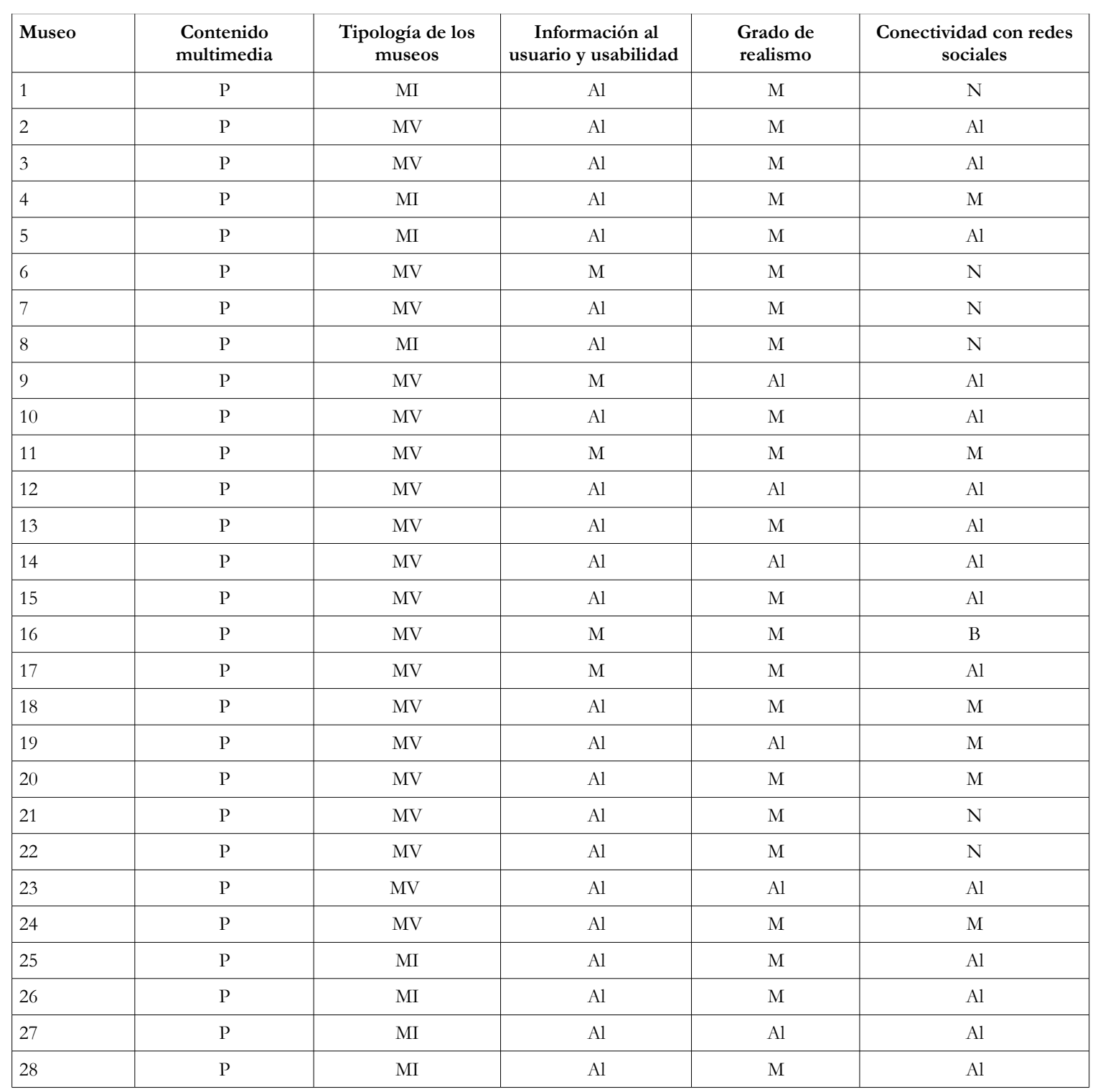


Anexo 3. Tabla de datos de la dimensión "Didáctica" de los museos virtuales de ciencias $(\mathrm{P}=$ Presente, $\mathrm{A}=$ Ausente, $\mathrm{Al}=$ Alto, $\mathrm{M}=$ Medio, $\mathrm{B}=\mathrm{Bajo}, \mathrm{N}=$ Nulo).

\begin{tabular}{|c|c|c|c|c|c|c|}
\hline \multirow[t]{2}{*}{ Museo } & \multirow{2}{*}{$\begin{array}{c}\text { Nivel de } \\
\text { procesamiento } \\
\text { cognitivo que exigen } \\
\text { las actividades }\end{array}$} & \multirow[t]{2}{*}{ Evaluación } & \multicolumn{3}{|c|}{$\begin{array}{l}\text { Tipos de contenidos que promueve } \\
\text { el museo }\end{array}$} & \multirow{2}{*}{$\begin{array}{l}\text { Acompa- } \\
\text { ñamiento } \\
\text { de guía } \\
\text { didáctica }\end{array}$} \\
\hline & & & $\begin{array}{l}\text { Concep- } \\
\text { tuales }\end{array}$ & $\begin{array}{c}\text { Procedimen- } \\
\text { tales }\end{array}$ & $\begin{array}{l}\text { Actitudi- } \\
\text { nales }\end{array}$ & \\
\hline 1 & $\mathrm{Al}$ & $\mathrm{N}$ & $\mathrm{P}$ & $\mathrm{P}$ & A & A \\
\hline 2 & $\mathrm{~N}$ & $\mathrm{~N}$ & $\mathrm{P}$ & A & A & A \\
\hline 3 & $\mathrm{~N}$ & $\mathrm{~N}$ & $\mathrm{~A}$ & $\mathrm{~A}$ & $\mathrm{~A}$ & $A$ \\
\hline 4 & $\mathrm{~B}$ & $\mathrm{~N}$ & $\mathrm{P}$ & A & A & A \\
\hline 5 & $\mathrm{~B}$ & $\mathrm{~B}$ & $\mathrm{P}$ & A & $\mathrm{A}$ & $\mathrm{A}$ \\
\hline 6 & $\begin{array}{c}\text { No funcionan los } \\
\text { enlaces }\end{array}$ & $\mathrm{N}$ & $\mathrm{P}$ & $\mathrm{A}$ & A & $\mathrm{A}$ \\
\hline 7 & $\mathrm{~N}$ & $\mathrm{~N}$ & A & A & A & A \\
\hline 8 & B & B & $\mathrm{P}$ & $\mathrm{P}$ & $\mathrm{P}$ & A \\
\hline 9 & $\mathrm{~B}$ & $\mathrm{~B}$ & $\mathrm{P}$ & A & $\mathrm{A}$ & $\mathrm{P}$ \\
\hline 10 & $\mathrm{Al}$ & $\mathrm{N}$ & $\mathrm{P}$ & $\mathrm{P}$ & $\mathrm{A}$ & $\mathrm{P}$ \\
\hline 11 & $\mathrm{~N}$ & $\mathrm{~N}$ & $\mathrm{P}$ & A & A & A \\
\hline 12 & $\mathrm{~N}$ & $\mathrm{~N}$ & $\mathrm{P}$ & A & A & $\mathrm{P}$ \\
\hline 13 & $\mathrm{~N}$ & $\mathrm{~N}$ & $\mathrm{P}$ & A & A & $\mathrm{P}$ \\
\hline 14 & $\mathrm{Al}$ & $\mathrm{N}$ & $\mathrm{P}$ & $\mathrm{P}$ & $\mathrm{P}$ & $\mathrm{P}$ \\
\hline 15 & $\mathrm{~N}$ & $\mathrm{~N}$ & $\mathrm{P}$ & A & A & A \\
\hline 16 & $\mathrm{Al}$ & $\mathrm{N}$ & $\mathrm{P}$ & $\mathrm{P}$ & $\mathrm{P}$ & $\mathrm{P}$ \\
\hline 17 & $\mathrm{~N}$ & $\mathrm{~N}$ & $\mathrm{P}$ & A & A & A \\
\hline 18 & $\mathrm{~B}$ & $\mathrm{~N}$ & $\mathrm{P}$ & $\mathrm{P}$ & A & $\mathrm{P}$ \\
\hline 19 & $\mathrm{~B}$ & $\mathrm{~N}$ & $\mathrm{P}$ & $\mathrm{P}$ & A & A \\
\hline 20 & $\mathrm{~N}$ & $\mathrm{~N}$ & $\mathrm{P}$ & $\mathrm{A}$ & $\mathrm{A}$ & A \\
\hline 21 & $\mathrm{~N}$ & $\mathrm{~N}$ & $\mathrm{P}$ & A & A & A \\
\hline 22 & $\mathrm{~N}$ & $\mathrm{~N}$ & $\mathrm{P}$ & A & $\mathrm{P}$ & $\mathrm{P}$ \\
\hline 23 & $\mathrm{~N}$ & $\mathrm{~N}$ & $\mathrm{P}$ & A & A & $\mathrm{P}$ \\
\hline 24 & $\mathrm{~N}$ & $\mathrm{~N}$ & $\mathrm{P}$ & $\mathrm{A}$ & $\mathrm{P}$ & $\mathrm{P}$ \\
\hline 25 & B & $\mathrm{N}$ & $\mathrm{P}$ & $\mathrm{P}$ & A & $\mathrm{P}$ \\
\hline 26 & B & $\mathrm{M}$ & $\mathrm{P}$ & $\mathrm{P}$ & $\mathrm{P}$ & $\mathrm{P}$ \\
\hline 27 & B & $\mathrm{N}$ & $\mathrm{P}$ & $\mathrm{P}$ & A & $\mathrm{P}$ \\
\hline 28 & B & $\mathrm{N}$ & $\mathrm{P}$ & $\mathrm{A}$ & $\mathrm{P}$ & $\mathrm{A}$ \\
\hline
\end{tabular}


Anexo 4. Tabla de datos de la dimensión "Ciencia" de los museos virtuales de ciencias $(\mathrm{P}=$ Presente, $\mathrm{A}=$ Ausente, $\mathrm{Ob}=$ Objetiva, $\mathrm{Ap}=$ Aplicada, $\mathrm{I}=$ Investigación, $\mathrm{D}=$ Divulgación, $\mathrm{ID}=$ Investigación y divulgación)

\begin{tabular}{|c|c|c|c|}
\hline Museo & $\begin{array}{l}\text { Visión de ciencia que } \\
\text { promueve }\end{array}$ & $\begin{array}{l}\text { Perspectiva histórica } \\
\text { de la ciencia }\end{array}$ & $\begin{array}{c}\text { Investigación y } \\
\text { divulgación }\end{array}$ \\
\hline 1 & $\mathrm{Ob}$ & A & D \\
\hline 2 & $\mathrm{Ob}$ & A & $\mathrm{D}$ \\
\hline 3 & $\mathrm{Ob}$ & A & D \\
\hline 4 & $\mathrm{Ob}$ & $\mathrm{P}$ & A \\
\hline 5 & $\mathrm{Ob}$ & A & A \\
\hline 6 & $\mathrm{Ob}$ & $\mathrm{A}$ & A \\
\hline 7 & $\mathrm{Ob}$ & A & I \\
\hline 8 & $\mathrm{Ob}$ & A & ID \\
\hline 9 & Ap & $\mathrm{P}$ & I \\
\hline 10 & $\mathrm{Ob}$ & A & A \\
\hline 11 & $\mathrm{Ob}$ & A & A \\
\hline 12 & $\mathrm{Ob}$ & A & ID \\
\hline 13 & $\mathrm{Ob}$ & A & ID \\
\hline 14 & $\mathrm{Ob}$ & $\mathrm{P}$ & A \\
\hline 15 & $\mathrm{Ob}$ & A & A \\
\hline 16 & Ap & $\mathrm{P}$ & A \\
\hline 17 & $\mathrm{Ob}$ & $\mathrm{P}$ & D \\
\hline 18 & $\mathrm{Ob}$ & A & ID \\
\hline 19 & $\mathrm{Ob}$ & $\mathrm{P}$ & ID \\
\hline 20 & $\mathrm{Ob}$ & $\mathrm{P}$ & I \\
\hline 21 & $\mathrm{Ob}$ & $\mathrm{P}$ & ID \\
\hline 22 & $\mathrm{Ob}$ & A & ID \\
\hline 23 & $\mathrm{Ob}$ & A & ID \\
\hline 24 & Ap & A & ID \\
\hline 25 & $\mathrm{Ob}$ & A & ID \\
\hline 26 & $\mathrm{Ob}$ & A & ID \\
\hline 27 & $\mathrm{Ob}$ & A & I \\
\hline 28 & $\mathrm{Ap}$ & A & A \\
\hline
\end{tabular}

